\author{
Military Technical College \\ Kobry Elkobbah, Cairo, \\ Egypt.
}

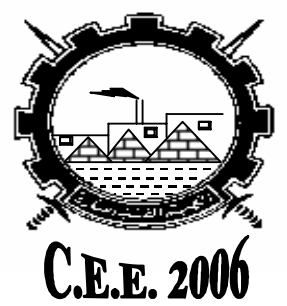

$3^{\text {rd }}$ International Conference

On

Chemical \& Environmental

Engineering

\title{
ALUMINUM PARTICLE SIZE EFFECT ON THE EXPLOSIVE CHARACTERISTICS OF HIGH EXPLOSIVE MIXTURES.
}

\author{
Seleet M. M. ", Ismail M. M. *, and Hashem M. E. *
}

\section{ABSTRACT}

The energy output of high explosives can be increased by the addition of certain metallic fuels to the explosive compositions. Aluminum is the most common fuel additive due to its high reliability and low cost as well as its high heat of combustion. In this paper, aluminized high explosive compositions based on RDX, TNT and aluminum powder $(12,40,75 \mu \mathrm{m})$ were prepared on the Lab scale. In these compositions, the weight percentage of aluminum was $5,10,15$, 20 and $25 \%$. Some of the explosive characteristics of the compositions were determined experimentally and theoretically. The effects of weight percentage and grain size on the characteristics of such compositions were recognized.

\section{KEY WORDS}

Explosives, Aluminized Explosives, Energized Explosives.

\section{NOMENCLATURE}

$\begin{array}{ll}Q_{V} & \text { Heat of explosion, } \mathrm{kJ} / \mathrm{kg} \\ \Delta \mathrm{Hc} & \text { Heat of combustion at constant pressure, } \mathrm{kJ} / \mathrm{kg} \\ \mathrm{V}_{\mathrm{O}} & \text { Specific volume of gases, } \mathrm{m}^{3} / \mathrm{kg} \\ \mathrm{T} & \text { Delay time period, } \mathrm{s} \\ \mathrm{E} & \text { Activation energy, } \mathrm{kJ} / \mathrm{mol} \\ \mathrm{K}_{\mathrm{w}} & \text { Heat capacity of water } \\ \mathrm{CJ} & \text { Chapman-Jouget state }\end{array}$

\footnotetext{
* Egyptian Armed Forces.
} 


\section{INTRODUCTION}

In general the energy of high explosives as represented by the thermodynamic free energy $\Delta G$ can be increased by raising the contribution of the heat of explosion, " $Q_{v}$ " [1-2]. In purely organic explosives, it is evident that the available heat of explosion " $Q_{v}$ " is limited by the heats of combustion of the constituent fuel elements (carbon and hydrogen). A simple way to increase the value of " $Q_{v}$ " is by adding, to the explosive, an elemental fuel which has a high heat of combustion [1-13].

If the heat of combustion of the fuel at constant pressure is " $\Delta \mathrm{Hc}$ " [kJ/mol], then the contribution of the fuel to the heat of explosion will be " $\Delta \mathrm{Hc} / \mathrm{m}$ " $[\mathrm{kJ} / \mathrm{g}]$ where "m" is the gram atomic mass of the fuel. Accordingly, the light elements of the periodic table provide the hottest fuels. Several metal fuels can be used with high explosives in order to increase their heat of explosion and performance [3]. However, aluminum is the most common fuel additive due to its higher availability and low cost as well as its relatively large heat of combustion.

In this paper different aluminized high explosive compositions based on RDX, TNT and aluminum powder $(12,40,75 \mu \mathrm{m})$ were prepared on the Lab scale. In these compositions, the weight percentage of Aluminum was 5, 10, 15, 20 and $25 \%$. The weight ratio of the RDX to TNT in the all compositions was kept constant $60 / 40$ in order to make a comparison with the reference explosive mixture compound B (RDX/TNT-60/40). Some of the explosive characteristics of the compositions were determined experimentally and theoretically. The effects of weight percentage and grain size on the characteristics of such compositions were recognized.

\section{EXPERIMENTAL.}

\subsection{Samples Preparation}

The prepared compositions were based on RDX, TNT and military grade aluminum powder $(12,40$ and $75 \mu \mathrm{m})$. To guarantee the homogeneity of the prepared compositions, compound B explosive (RDX/TNT - 60/40) was used as source of both RDX and TNT. The weight percentage of aluminum powder was changed for every particle size as shown in Table (1). Compound B was melted in a suitable glass flask $(300 \mathrm{ml})$ in a water bath and kept at $90{ }^{\circ} \mathrm{C}$ for approximately 30 minutes. After complete melting of the explosive, the amount of aluminum was added gradually during mechanical stirring. Upon the complete addition of aluminum, the mixture was then stirred for a approximately $30 \mathrm{~min}$. The molten mixture was then poured into PVC tubes of length $200 \mathrm{~mm}$ and internal diameter of $20 \mathrm{~mm}$, where the mixture begins to solidify. At this moment hand pressing of the mixture inside the PVC tubes started in order to avoid air bubbles and to get suitable density. Each PVC tube accommodates approximately $125 \mathrm{~g}$ of the prepared formulation and the rest of the formulation was kept for the rest of the tests. The prepared aluminized high explosive sample was accurately weighed. 


\subsection{Determination of Sensitivity to Impact}

Sensitivity to impact test was carried out using IKA-MASCHINENBAU apparatus. The experiment was conducted using a weight of a constant mass $(5 \mathrm{~kg})$ and by changing the drop height. For each drop height, six consecutive trials were performed. The minimum height at which $100 \%$ initiations occurred was determined (the upper sensitivity limit); thus the energy required to initiate the explosives could be estimated. It is to be noted here that the explosive sample used in this test was taken from the casted mold, and grinded to the required grain size suitable for the test.

\subsection{Determination of Sensitivity to Friction}

Sensitivity to friction test was determined using BAM friction test apparatus (Chilworth Technology). The test was conducted in such a way that the loading on the pistil was varied and the percentage of initiation was determined. Ten consecutive trials were performed for each loading. The load at which $100 \%$ initiation occurred was determined and thus the force in Newton could be estimated.

\subsection{Determination of Sensitivity to Thermal Stimuli}

The sensitivity to heat was obtained by determining the deflagration temperature for the prepared samples using deflagration test apparatus (Chilworth Technology). In determining the ignition temperature, a sample of the explosive was heated while the temperature was uniformly increased $\left[5^{\circ} \mathrm{C} / \mathrm{min}\right]$, up to the development of the explosive conversion. The ignition temperature was determined as the average of three parallel test samples.

\subsection{Heat of Combustion Measurements}

The measurements were carried out using an Autobomb (Sanyo Gallenkamp PLC) and Gallenkamp Autothemocalc II. This instrumentation offers the automatic calculation and manipulation of the data using a personal computer. The combustion of the samples was carried out in an atmosphere of oxygen at a pressure of approximately 25 bars. The calibration of the instrument and the measurements were carried out according to the standard procedures.

\subsection{Measurements of the Velocity of Detonation}

The measurments were carried out using "explomet-fo-multichannel" apparatus (KONTINITRO AG). This instrumentation has six synchronous timers which measure time intervals between the illumination of seven optical probes. For each timer, it displays the measured time in microseconds and calculates the velocity in $\mathrm{m} / \mathrm{s}$. To perform this test the explosive mixtures were casted into PVC tubes of internal diameter $20 \mathrm{~mm}$ and length of $200 \mathrm{~mm}$. The densities of the explosive charges in $\left(\mathrm{g} / \mathrm{cm}^{3}\right)$ are given in Table (2). On using this technique, Initiation was performed using standard number eight plain detonator and a suitable booster charge of pressed Hexogen. It is to be noted here that for each mixture two results were performed and the average result of the two was recorded.

\subsection{Brisance Test}

This test was carried out using the brisance testing unit according to KAST [ 14 ]. The testing unit consists of an easily movable steel cylinder which is placed onto a copper cylinder in a precisely centered position with the aid of a special guiding cylinder. In order to centre the test charge and to obtain a direct contact between the test charge and the steel cylinder without including any gaps, a special preload body is used. The 
individual components are arranged in a solid pulse-resisting steel frame to guarantee a good reproducibility of the experimental data recorded. The compression values of the copper cylinder are measured by means of a micrometer screw and used to determine the brisance value from appropriate tables.

\section{RESULTS AND DISSCUSSIONS}

\subsection{Sensitivity to Impact Results}

The results of this test are illustrated in Figure (1). It can be seen that the sensitivity of aluminized high explosives to impact decreases by increasing the weight percentage of the aluminum. Therefore, $\mathrm{Al}$ is a good additive for desensitization of sensitive high explosives. This may be attributed to the fact that aluminum is an inert material and acts as a flegmatizer. This result is in an agreement with reference 4. Also, it is shown that the formulations with the smallest particle size of $\mathrm{Al}(12 \mu \mathrm{m})$ are more sensitive to impact, while formulations with the larger particle size of $\mathrm{Al}$ (40 and $75 \mu \mathrm{m}$ ) need more impact energy to be initiated. This may be attributed to the possibility that the hot spots, produced on the microscopic level, may lose some of its energy to the neighboring aluminum particle. So, the larger the aluminum particle size, the larger its thermal conductivity, and the larger the lost energy. Consequently, formulations with larger particle size need more impact energy, i.e. have lower sensitivity.

\subsection{Sensitivity to Friction Results}

The results are tabulated in Tables $(6,7$, and 8 ) and illustrated in Figure (2). It is obvious that the sensitivity of aluminized high explosives decreased with increasing the weight percentage of $\mathrm{Al}$ [4]. This may be attributed to the fact that $\mathrm{Al}$ is an inert material and acts as a flegmatizer. Also, it is shown that the formulations with the largest particle size of Al used $(75 \mu \mathrm{m})$ are less sensitive to friction. This may be explained on the fact that any two surfaces, when rubbed together, generate high temperature. Adding an inert material, with high thermal conductivity as aluminum, will have a cooling effect, hence more applied load is required, i.e. with increasing the aluminum particle size, the cooling effect increases, and consequently the sensitivity decreases. From these results it is evident that addition of Al to explosives, besides providing high energy, has a markedly great effect in decreasing the sensitivity of explosives to friction (more than 2 times less sensitivity). Therefore, Al could be considered as a flegmatizer for sensitive high explosives.

\subsection{Sensitivity to Thermal Stimuli Results}

The results are illustrated in Figure (3). It is clear that the ignition temperatures of compound $\mathrm{B}$ and all the formulations of aluminized high explosives (different $\mathrm{Al}$ particle size) are very close to each other in the range of (226-239) ${ }^{\circ} \mathrm{C}$. Thus, the addition of $\mathrm{Al}$ to the explosives has an insignificant effect on the ignition temperature of such explosives. However, this slight effect may be attributed to the high thermal conductivity of $\mathrm{Al}$ which could facilitate the ignition process. Also, it is evident that formulations based on $\mathrm{Al}(12 \mu \mathrm{m})$ showed the highest sensitivity to heat. This may be 
attributed to the fact that smaller grain size of Al would provide larger surface area which may help in the ignition process of the formulations.

\subsection{The Heat of Combustion Results}

The results are illustrated in Figure (4). It is obvious that there is a significant increase in the heat of combustion with the increase in the weight percentage of aluminum. This increase ranges from $2-20 \%$ and may be varied depending on the conditions of the test and the characteristics of aluminum. However, the maximum weight percentage of aluminum to be added can be determined when other parameters, such as the specific volume of gases and the velocity of detonation, are considered.

Also, it is evident that the heat of combustion values are higher for the smallest particle size of the used $\mathrm{Al}(12 \mu \mathrm{m})$. This may be due to the fact that with the smallest particle size of $\mathrm{Al}$, the total available surface area will increase, consequently, the total number of superficial aluminum will increase. So, both the combustion heat and weight residue of solid products will increase.

\subsection{The Velocity of Detonation Results}

The results are illustrated in Figure (5). It can be seen that the velocity of detonation decreases with increasing the weight percentage of $\mathrm{Al}$ in the explosive formulation. For formulations containing 20 and 25 weight percent of aluminum of particle size 40 and $75 \mu \mathrm{m}$, the velocity of detonation is $30 \%$ less than the reference explosive. Aluminum will not directly represent a reaction partner in the detonation zone as the other explosive ingredients have already negative oxygen balance on their own. Therefore, the Al powder is reducing the reacting molecules. The Al particles, on their own, will be compressed by the shock or detonation wave but contribute to the reaction behind the detonation front. Consequently, the detonation velocities of aluminized compositions are less than that of nonaluminized compositions.

Also, it was shown that the detonation velocity of aluminized formulations based on the smallest particle size of used $\mathrm{Al}(12 \mu \mathrm{m})$ are higher than those based on larger Al particle size at the same Al weight percentage. This may be due to the fact that smaller particle size of Al could increase the density of explosive formulation which results in an increase in the velocity of detonation.

\subsection{The Brisance Test Results}

Only samples containing $\mathrm{Al}(12 \mu \mathrm{m})$ were tested. The results are presented in Table (2). It can be seen that the brisance of the tested samples slightly increased (3-7 \%) up to a weight percentage of $15 \% \mathrm{Al}$, then the brisance started to decrease again. The slight increase in brisance may be attributed to the high energy output of the exothermic reactions in presence of Al. This slight increase manifests itself by the slight decrease in the velocity of detonation.

The slight decrease in brisance (2-3\%) for samples containing more than $15 \% \mathrm{Al}$ may be explained by the fact that a sharp decrease in the velocity of detonation could not be compensated by the high exothermicity of the reactions. In other words, in this regime (high percentage of $\mathrm{Al}>15 \%$ ) the detonation velocity has the dominant effect on the brisance. 


\section{CONCLUSIONS}

In general, the presented work has revealed the following important conclusions:

1. The processing and casting of the aluminized explosives were reasonable until $15 \% \mathrm{Al}$ weight percentage. When the weight percentage of $\mathrm{Al}$ exceeds $15 \%$ the processing was more difficult. This difficulty was not recognized in case of using $(12 \mu \mathrm{m})$ particle size $\mathrm{Al}$ even at $25 \%$ of $\mathrm{Al}$.

2. Addition of $\mathrm{Al}(12,40$ and $75 \mu \mathrm{m})$ decreases sensitivity to impact and friction compared with the reference explosive compound $B$. This decrease is proportional to Al content. Therefore, Al with certain particle size could act as a flegmatizer when added to explosives.

3. The aluminized formulations based on $\mathrm{Al}(12 \mu \mathrm{m})$ are more sensitive to mechanical stimuli than those based on 40 and $75 \mu \mathrm{m}$. this may be due to the increase in the surface area of the particles and consequently an increase in the entrapped air which acts as hot spots upon initiation.

4. The addition of $\mathrm{Al}$ to the explosives has no significant effect on the ignition temperature of such explosives. However, Formulations with different content of $(12 \mu \mathrm{m})$ particle size Al showed the highest sensitivity to heat.

5. Aluminum has a great effect on increasing the heat of combustion/explosion of the explosives. Also, the heat of combustion increases with the decrease of particle size of the used Al.

6. The velocity of detonation decreases by increasing the Al content in the explosive formulation. The detonation velocities of aluminized formulations based on the smallest particle size of used Al powder, namely $(12 \mu \mathrm{m})$ are higher than those based on larger Al particle size.

7. The brisance of the aluminized high explosives was slightly increased $(3-7 \%)$ up to $15 \% \mathrm{Al}$, then started to decrease again.

Thus from the point of view of processing, performance, sensitivity, and cost, the optimal weight percentage of aluminum must be approximately $10-15 \%$.

\section{REFERENCES}

[1] Turnbull J. H. and Walter K., "The Thermochemistry of High Explosives", Shrivenham, (1982).

[2] Nicolich S., Doll D. and Gunger M., "Recent Development in Reduced Sensitivity melt pour explosives",34 $\underline{\text { rd }}$ International Conference of ICT, Karlsruhe, Germany, (2003).

[3] Drezen E. L., "Phase Changes in Metal Combustion", Aerochem Research Laboratory, USA, (2000).

[4] Held M., "Aluminized High Explosives Charges", 33 rd Annual International Conference of ICT, Karlsruhe, Germany, (2002).

[5] Youhua Q. and Shiquan L., "Study on Dispersed Combustion Characteristics of Al Powder by the Explosion of Central Charge", 33맘 International Conference of ICT, Karlsruhe, Germany, (2002).

[6] Brousseau P. and Cliff M. D., "The Effect of Ultrafine Al Powder on the Detonation Properties of Various Explosives", 32 nd Annual International Conference of ICT, Karlsruhe, Germany, (2001). 
[7] Ramaswamy A. L. and Kaste P., "Combustion Modifiers for Energetic Materials", 34 $\underline{\text { Th }}$ International Conference of ICT, Karlsruhe, Germany, (2003).

[8] Ishida T. and Kato Y., "Detonation Pressure of Aluminized Explosives by Means Of Shock-Induced Polarization", 23 $3^{\text {rd }}$ International Conference of ICT, Karlsruhe, Germany, (1992).

[9] Maranda A. and Stanislaw, "Behavior of Al and TNT in the Detonation Wave of Ammonium Nitrate Explosives", 27는 International Conference of ICT, Karlsruhe, Germany, (1996).

[10] Trzcinski W. A. and Paszula. J, "Confined Explosions of Aluminized High Explosives", 31 st International Conference of ICT, Karlsruhe, Germany, (2000).

[11] Langer G., "The Influence of Particle Size of A.P and Al on the Performance of

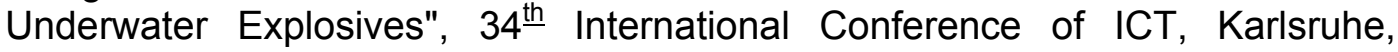
Germany, (2003).

[12] Sirringhous U. and Wild.R, "Influence of Al /AP on the Performance of Underwater Explosives", Propellants, Explosives, Pyrotechnics 24,140-143, (1999).

[13] Alexandre L., "Expertise of Nanometric Al Powder on the Detonation Efficiency of Explosives", 32 $\frac{\text { nd }}{}$ Annual International Conference of ICT, Karlsruhe, Germany, (2001).

[14] SuĆeska M. , "Test Methods for Explosives". Springer-Verlag, New York Inc., (1995). 


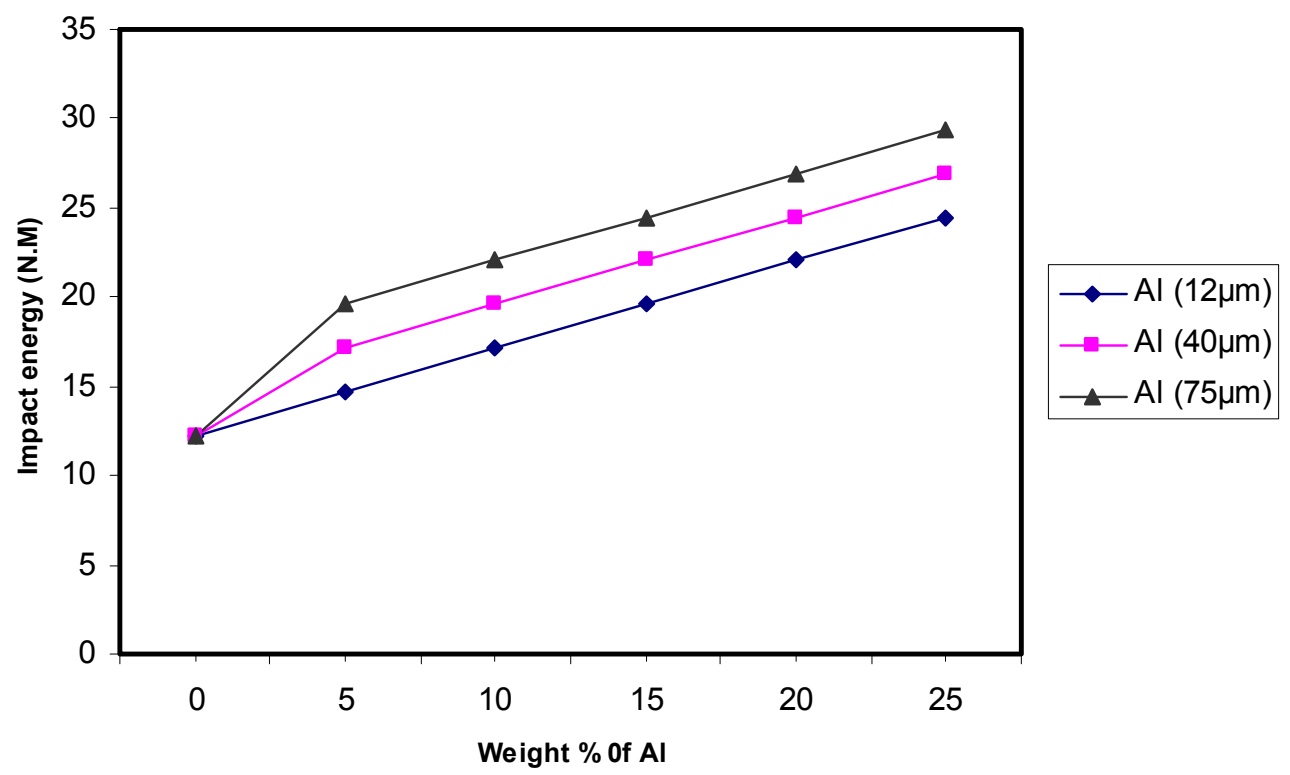

Fig. 1. Impact energy of $100 \%$ initiation vs. aluminum content of aluminized mixtures for different particle size.

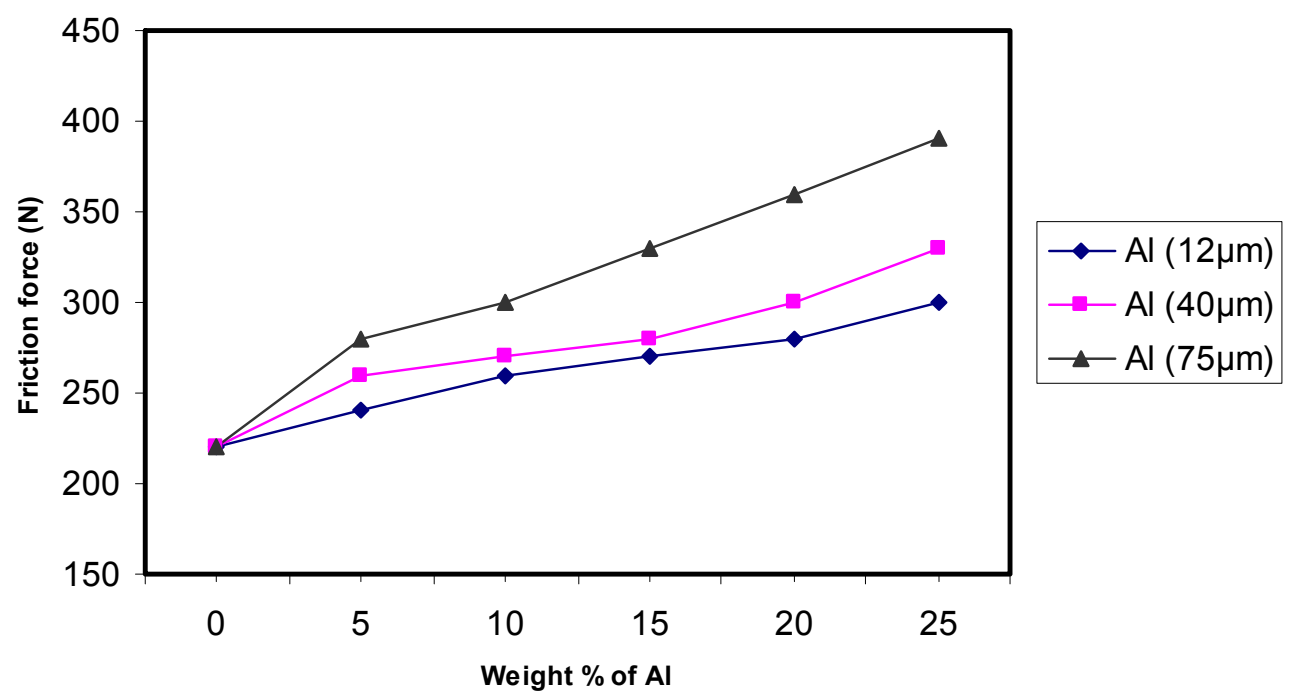

Fig. 2. Minimal applied load of $100 \%$ initiation vs. aluminum content for aluminized mixtures of different particle size. 


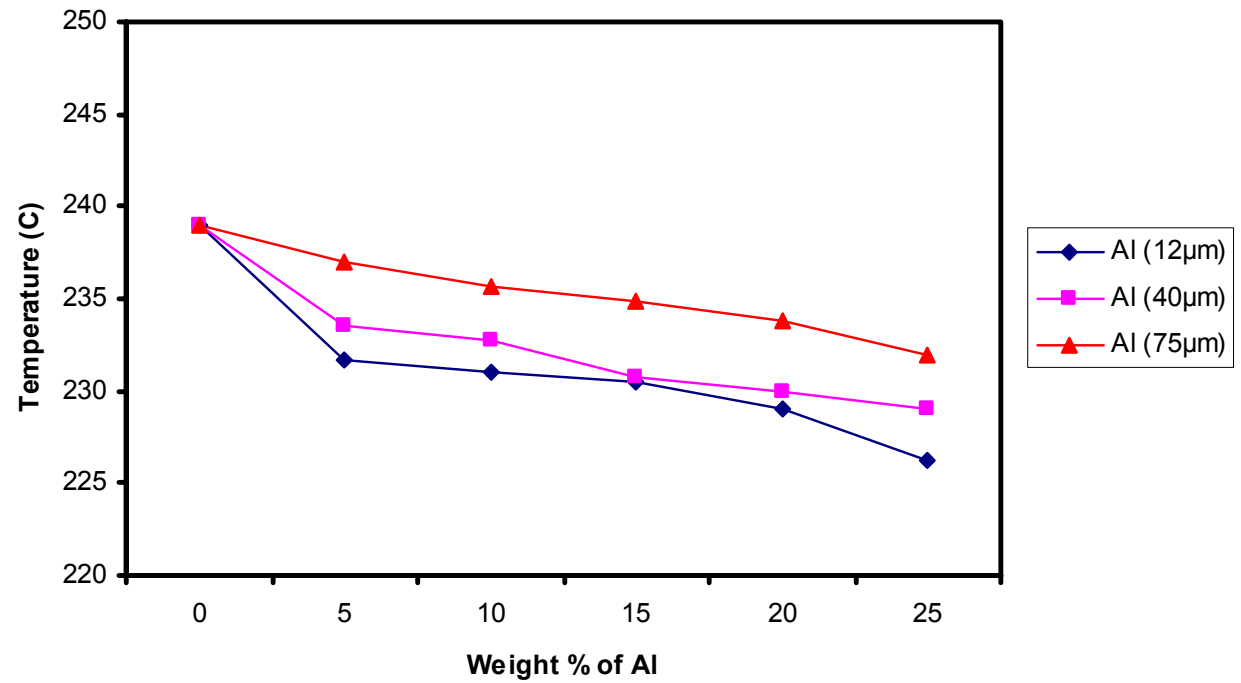

Fig. 3. Ignition temperature of different aluminized high explosive formulations vs. aluminum content for different particle size.

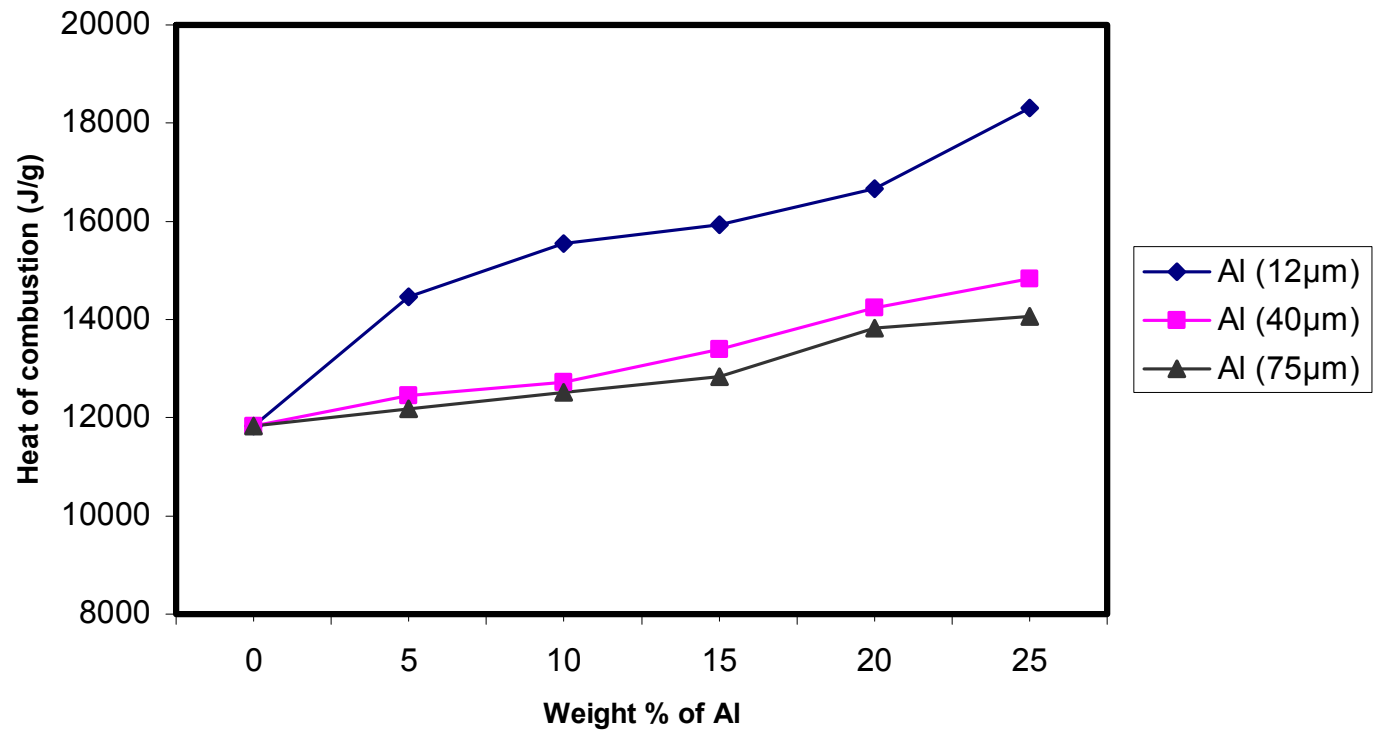

Fig. 4. Variation of combustion heat, of aluminized mixtures, with the aluminum content (wt \%), for different particle size. 


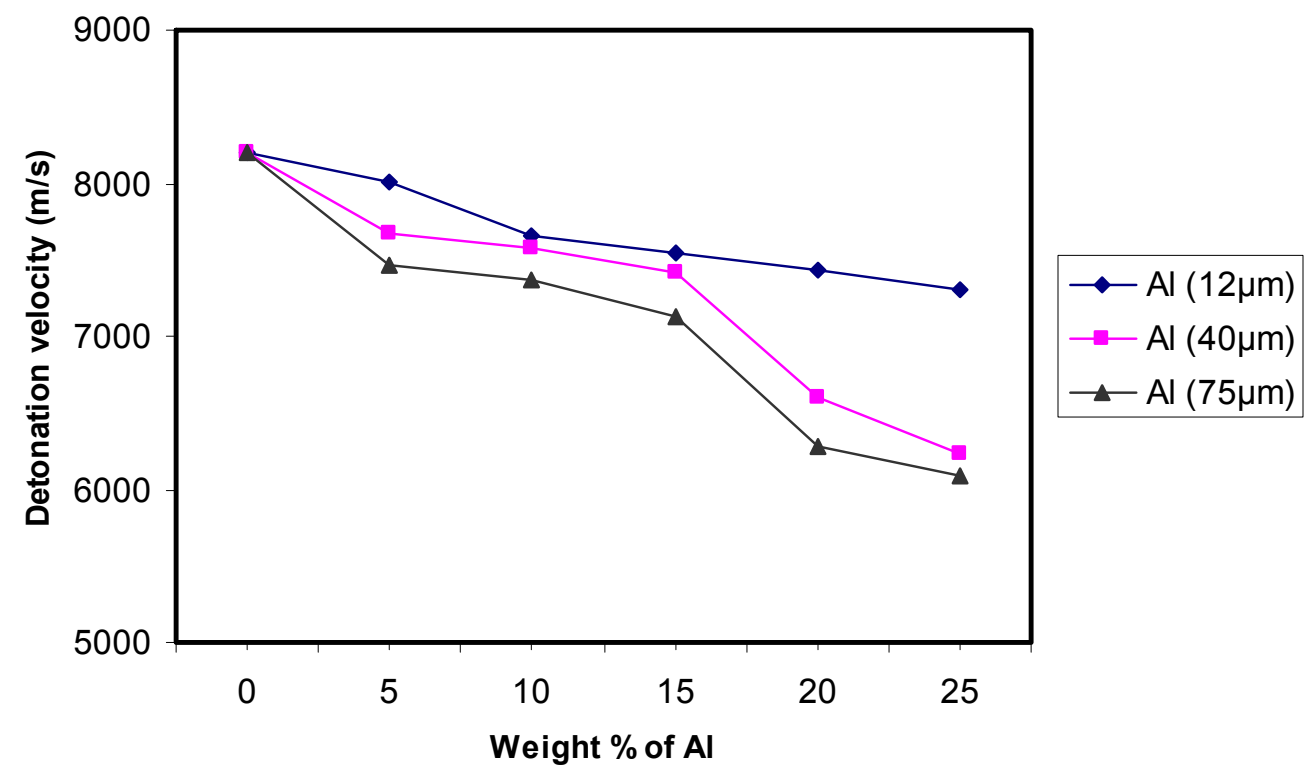

Fig. 5. Variation of detonation velocity, of aluminized mixtures, with the aluminum content (wt \%), for different particle size. 
Table 1. Compositions of prepared aluminized mixtures.

\begin{tabular}{|c|c|c|c|c|c|}
\hline \multirow[b]{2}{*}{ Sample } & \multirow{2}{*}{$\begin{array}{c}\mathrm{Al} \\
\text { particle size, }(\mu \mathrm{m})\end{array}$} & \multicolumn{3}{|c|}{ Weight percentage } & \multirow[b]{2}{*}{ Density $\left(\mathbf{k g} / \mathrm{m}^{3}\right)$} \\
\hline & & RDX & TNT & Al & \\
\hline $\mathrm{S}_{0}$ & - & 60 & 40 & - & 1600 \\
\hline $\mathrm{S}_{1}$ & \multirow{5}{*}{12} & 57 & 38 & 5 & 1680 \\
\hline $\mathrm{S}_{2}$ & & 54 & 36 & 10 & 1700 \\
\hline $\mathrm{S}_{3}$ & & 51 & 34 & 15 & 1800 \\
\hline $\mathrm{S}_{4}$ & & 48 & 32 & 20 & 1850 \\
\hline$S_{5}$ & & 45 & 30 & 25 & 1900 \\
\hline$S_{6}$ & \multirow{5}{*}{40} & 57 & 38 & 5 & 1650 \\
\hline$S_{7}$ & & 54 & 36 & 10 & 1680 \\
\hline $\mathrm{S}_{8}$ & & 51 & 34 & 15 & 1700 \\
\hline$S_{9}$ & & 48 & 32 & 20 & 1750 \\
\hline $\mathrm{S}_{10}$ & & 45 & 30 & 25 & 1800 \\
\hline$S_{11}$ & \multirow{5}{*}{75} & 57 & 38 & 5 & 1620 \\
\hline $\mathrm{S}_{12}$ & & 54 & 36 & 10 & 1650 \\
\hline $\mathrm{S}_{13}$ & & 51 & 34 & 15 & 1680 \\
\hline$S_{14}$ & & 48 & 32 & 20 & 1700 \\
\hline$S_{15}$ & & 45 & 30 & 25 & 1750 \\
\hline
\end{tabular}

Table 2. Brisance of aluminized mixtures containing aluminum of particle size $12 \mu \mathrm{m}$.

\begin{tabular}{|c|c|c|}
\hline Sample code & Al \% & Pressure (kPa) \\
\hline $\mathrm{S}_{0}$ & 0 & 1059 \\
\hline $\mathrm{S}_{1}$ & 5 & 1088 \\
\hline $\mathrm{S}_{2}$ & 10 & 1127 \\
\hline $\mathrm{S}_{3}$ & 15 & 1136 \\
\hline $\mathrm{S}_{4}$ & 20 & 1039 \\
\hline $\mathrm{S}_{5}$ & 25 & 1023 \\
\hline
\end{tabular}

